\title{
ENHANCEMENT IN ARSENIC REMEDIATION BY MAIZE (ZEA MAYS L.) USING EDTA IN COMBINATION WITH ARBUSCULAR MYCORRHIZAL FUNGI
}

\author{
WANG, S. ${ }^{1}-$ PAN, S. ${ }^{1}-$ SHAH, G. M. ${ }^{1,2}-$ ZhANG, Z. ${ }^{1}-$ YANG, L. ${ }^{1}-$ YANG, S. ${ }^{1 *}$ \\ ${ }^{l}$ Yantai Institute, China Agricultural University, 264670 Yantai, Shandong Province, China \\ ${ }^{2}$ Department of Environmental Sciences, COMSATS University Islamabad, Vehari-Campus \\ 61100 Vehari, Pakistan \\ *Corresponding author \\ e-mail: sjyang-2008@163.com \\ (Received $26^{\text {th }}$ Jun 2018; accepted $31^{\text {st }}$ Aug 2018)
}

\begin{abstract}
This study was conducted to evaluate the effects of combination of ethylene diamine tetra acetic acid (EDTA) with arbuscular mycorrhizal fungi (AMF) on arsenic (As) phytoremediation using maize plants in pot experiment with four treatments (Control, EDTA, AMF, and EDTA+AMF). The results showed that lone addition of EDTA significantly increased exchangeable As concentration in the rhizosphere soil, and thus, enhanced plant uptake of As in shoots and roots. However, it markedly inhibited the root colonization, plant growth, and antioxidant enzyme activity. Consequently, As biological enrichment factor was the lowest because of reduced plant dry weight, although the plants possessed the highest As extraction efficiency. Unlike EDTA, AMF alone had a positive effect on root colonization, dry matter accumulation, and antioxidant enzyme activity, whereas negative effects of AMF on exchangeable As content in the rhizosphere soil and As uptake in shoots and roots were observed. However, using EDTA-AMF combination, maize plants simultaneously exhibited significantly higher exchangeable As extraction efficiency and biological enrichment factor, which were beneficial for the remediation of heavy metal-contaminated soil. Therefore, it is concluded that the EDTA-AMF combination could be regarded a promising choice for phytoremediation of heavy metal-polluted soil.
\end{abstract}

Keywords: EDTA, AMF, heavy metal, hyperaccumulator, phytoremediation, soil remediation

\section{Introduction}

Soil becomes polluted when potentially toxic substances are released in amounts exceeding their permissible levels, and reaching prohibitively high concentrations, which affect normal ecosystem functions (Meier et al., 2012). According to most legislative schemes, soil may require remediation if the concentration of one or more metals exceeds the specified threshold level in the soil profile (Meier et al., 2012). Regarding the increasing need to combat heavy-metal pollution, various strategies for soil remediation, mainly mechanical or physicochemical methods, including soil washing, vitrification, thermal treatment, excavation and confinement of soil, and so on, have been used to treat contaminated soil in recent decades (Bhargava et al., 2012; Sarwar et al., 2017). These techniques are usually expensive, require technical expertise and disturb the soil, occasionally rendering the land useless as a medium for further events such as plant growth (Marques et al., 2009). Therefore, mechanical and physicochemical treatments are not applicable on a large scale.

In contrast, phytoremediation is proposed to be efficient, cost-effective, with greater public acceptance, environmental-friendly and sustainable technology from remediation of metal contaminated soils (Pandey, 2012; Sinha et al., 2013; Shabir et al., 2018). In these techniques, plant roots absorb metals from the soil and accumulate them into their 
vegetative parts which are then harvested, and thereby metal is removed from the site of contamination (Shabir et al., 2018). The prerequisite for phytoremediation is that the plants must be genetically capable of growing in soils with high concentrations of metals, and have ability to accumulate metals in their shoots and roots without toxicity to their metabolic processes (Seth, 2011; Tang et al., 2012). The known plants meeting these requirements are called hyperaccumulators. However, growth and biomass production of hyperaccumulators are slow, and consequently, phytoremediation requires several years to reduce soil metal concentrations to an acceptable levels (McGrath and Zhao, 2003). This long duration is a drawback of metal-polluted soil remediation. Nevertheless, owing to preferred occurrence in residual forms, and strong binding with non-biotic or biotic ligands in soil, or inclusion within the crystal lattices of primary or secondary soil minerals, heavy metal bioavailability in soils is actually reduced (Charriau et al., 2011; Echevarria et al., 2006; Shahid et al., 2012). Additionally, the relatively low solubility and phytoavailability of heavy metals in soil is unfavorable for phytoremediation.

To compensate for the relatively small biomass of hyperaccumulators and low metal availability in soil, one alternative scenario has been hypothesized, wherein the plant selected for remediation can have large biomass production, and a chelating agent combined with soil amendment is used. This hypothesis is infact based on the concepts that (1) high plant biomass can enhance metal extraction from polluted soil, (2) chelating agents are used to improve the mobility, solubility, and bioavailability of heavy metals in the soil solution phase, and (3) amendment is applied to increase plant tolerance to heavy metal stress.

Actually, ethylene diamine tetra acetic acid (EDTA) is widely used as the most efficient and effective chelating agent to extract metals from contaminated soil. After soil application, EDTA transfers the metal sorption and precipitation equilibrium toward the enhanced dissolution of heavy metals owing to metal-EDTA complex formation (Goel and Gautam, 2010; Hadi et al., 2010). However, certain researchers reported that there was no significant effect of EDTA on metal uptake by plants, and in certain cases, even negative effects of EDTA application were observed (De La Rosa et al., 2007; Tomé et al., 2009). These contradictory findings indicate that the effect of EDTA on heavy-metal uptake varies with soil type, plant variety, heavy metal concentration and soil $\mathrm{pH}$.

Arbuscular mycorrhizal (AM) fungi (AMF) can develop extensive extraradical hyphal networks, which explore the soil to a greater extent, absorb nutrients from a large vacinity, and translocate them to the roots of host plants. Therefore, they are considered intermediary between soil nutrients and host plants. Moreover, AMF shows great potential for use in phytoremediation due to (i) their ubiquity in the soil environments, and (ii) the development of several strategies enabling host plants to tolerate high metal concentrations in the soil (Hildebrandt et al., 1999; Janousková et al., 2005). Nevertheless, the role of AMF in phytoremediation is still not completely understood. Many studies have demonstrated that AMF promote phytoextraction, causing an increase in metal translocation to shoots (Davies et al., 2001; Trotta et al., 2006). However, other researchers have showed that AMF develop mechanisms that only enable metal accumulation within plant roots, and prevent metal translocation to the shoots (Citterio, 2005; Giasson et al., 2005). To the best of our knowledge, research investigating role of EDTA or AMF in phytoremediation of metal contaminated soils 
are scarce, whereas no solid data set exists regarding their combined application for the aforementioned purpose.

With growing concern about remediation techniques for heavy metal-polluted soil, Knowledge of the processes and factors behind the combination of EDTA and AMF for enhancing the phytoremediation of heavy metal-polluted soil is crucial to evaluate and manage the outcomes of this technique. Therefore, this study aimed to highlight the role of the combination of EDTA and AMF in the phytoremediation of soil contaminated with arsenic (As), and additionally, to possibly provide new insight into the remediation of heavy metal-polluted soil.

\section{Material and methods}

\section{Experimental design}

The experiment was based on a randomized complete block design with three replications, and included four treatments. (i) Control: no EDTA and no AMF, (ii) EDTA: EDTA alone, (iii) AMF: AMF alone, and (iv) EDTA + AMF: EDTA-AMF combination.

\section{AMF inoculum and domestication}

The AMF inoculum Glomus versiforme was isolated from uncontaminated fluvoaquic soil at the Yantai Institute, China Agricultural University, Thereafter, a pot culture was prepared with Trifolium repens L. grown in a sterilized soil-sand mixture at 1:9 contaminated with arsenic (As) at $50 \mathrm{mg} \mathrm{kg}^{-1}$. After 90 days, chopped root pieces of $T$. repens along with soil were defined as the inoculum, containing a mixture of AM spores, colonized root pieces, AM mycelia, and 700-750 spores per $100 \mathrm{~g}$ of inoculum.

\section{Pot culture experiment}

To explore the objective as outlined above, an indoor pot experiment was conducted under controlled conditions in a greenhouse at the Yantai Institute, China Agricultural University. For this purpose, plastic pots were used with height and surface diameter of 30 and $23 \mathrm{~cm}$, respectively. Soil used in this study had $6.44 \mathrm{pH}$ (soil:water, 1:2.5), 2.1\% organic matter, $140 \mathrm{mg} \mathrm{kg}^{-1}$ available nitrogen, $58 \mathrm{mg} \mathrm{kg}^{-1}$ Olsen phosphorus, $158 \mathrm{mg}$ $\mathrm{kg}^{-1}$ available potassium, and $5.2 \mathrm{mg} \mathrm{kg}^{-1}$ total As. After collection from the field soil was air-dried, and then sterilized at $121{ }^{\circ} \mathrm{C}$ for $25 \mathrm{~min}$. Required amounts of $\mathrm{Na}_{2} \mathrm{HAsO}_{4} \cdot 7 \mathrm{H}_{2} \mathrm{O}\left(50 \mathrm{mg} \mathrm{kg}{ }^{-1}\right.$ of soil) were dissolved in $1000 \mathrm{ml}$ of distilled water, and then sprayed onto the soil. Subsequently, the soil was mixed thoroughly, and each pot was filled with $25 \mathrm{~kg}$ of the soil. The pots were incubated for 60 days to improve the balance of As in the contaminated soil. During incubation, moisture in the pots was maintained roughly at pot capacity. As was allowed to penetrate deep into the pots via watering, and then, transferred to the soil surface by volatilization, and thereby, was distributed uniformly in the soil. Regarding the AMF, $100 \mathrm{~g}$ of inoculum was uniformly introduced at a depth of $3 \mathrm{~cm}$. Thereafter, 5 seeds of maize (Zea mays L. 'Denghai3622 ') were sown in each pot. Before sowing the seeds were surface-sterilized with $0.5 \% \mathrm{NaClO}$ solution, subsequently washed several times with distilled water, and allowed to germinate at $28{ }^{\circ} \mathrm{C}$ for $48 \mathrm{~h}$. Seven days after emergence, maize were thinned to 3 plants per pot. In each pot, soil moisture was maintained daily at $70 \%$ of the pot capacity with distilled water based on weight, and amount of nutrients were added 
according to chemical analysis and plant requirements. Fifty days after emergence EDTA $\left(5 \mathrm{mmol} \mathrm{kg}{ }^{-1}\right)$, prepared in distilled-deionized water, was sprayed on the soil surface as per treatment plan

\section{Data collection and analytical methods}

From each pot, maize plants were harvested at 65 days after germination to estimate shoot and root biomass. Shoots were clipped with a pair of scissor at ground level (Shah et al., 2016). To harvest the roots, the whole soil clump from the pot was taken out and placed in a container filled with cold water. After $2 \mathrm{~h}$ of soaking, the clump was manually divided into 6 pieces. These pieces were taken out of the container one by one and placed on a $0.5 \mathrm{~mm}$ mesh frame to separate roots from soil with a jet of tap water and then, with deionized water as described by Shah et al. (2013). Percentage root colonization by AMF was calculated using the gridline intersect method after staining the roots with trypan blue (Koske and Gemma, 1989). The activities of superoxide dismutase (SOD) and catalase (CAT) in fresh shoots and roots were measured as described by Beauchamo and Fridovich (1971) and Aebi (1974), respectively. The remaining parts were dried in an oven at $80{ }^{\circ} \mathrm{C}$ for $48 \mathrm{~h}$, and then weighed to obtain dry matter of shoots and roots. As concentrations in the dried plant materials were determined by inductively coupled plasma atomic emission spectrometry (ICP-AES) (Yang, 1986). Rhizosphere soil was collected following the procedures described by Wang and Zabowski (1998). Classification of the heavy metal species in the dried soil was performed using continuous extraction (Yang et al., 2003). The extraction efficiency of the heavy metal and biological enrichment factor were calculated using Equations 1 and 2, respectively.

$$
\begin{gathered}
\text { Extraction efficiency }\left(\mathrm{mg} \mathrm{g}^{-1}\right)=\frac{\text { shoot heavy metal uptake }}{\text { root dry weight }} \\
\text { Biological enrichment factor }=\frac{\text { amount of heavy metal in plant }}{\text { amount of heavy metal in soil }}
\end{gathered}
$$

\section{Statistical analysis}

Values of the collected data are expressed as means of the three replicates. Effects of EDTA, AMF and their combinations were tested using analysis of variance (ANOVA). Means were compared among the treatments using the LSD (least significant difference) test at the 0.05 probability level.

\section{Results}

\section{Percentage root colonization}

Results revealed the significant effects of AMF on the extent of root colonization (Fig. 1). Mycorrhizal colonization was not observed in the control and EDTA treatments, due to the lack of mycorrhizal inoculation. However, plants treated with AMF alone and EDTA-AMF combination showed high colonization rates. In the former case, percentage root colonization was 1.6 folds higher than in case of EDTA-AMF combination. 


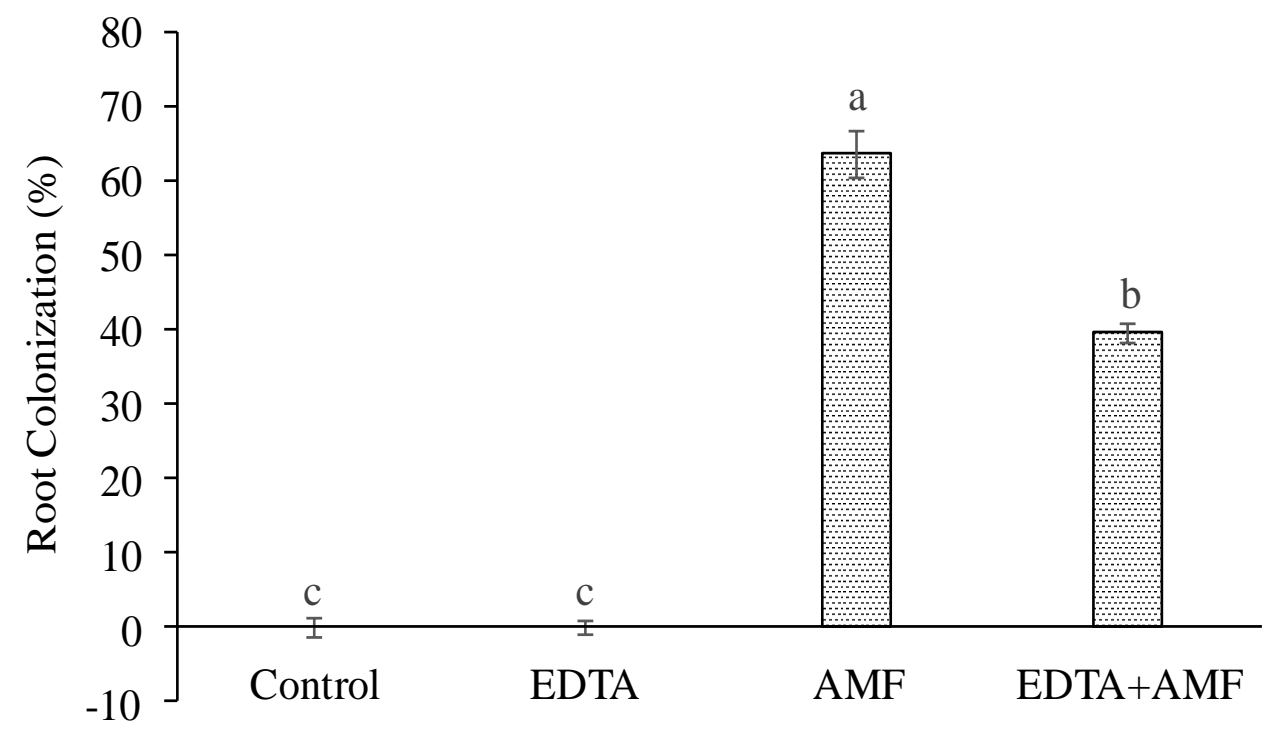

Figure 1. Root colonization percentage affected by AMF and EDTA application. All the values are the mean of triplications. Different letters above columns indicate significant differences between means by LSD at $5 \%$ level

\section{Dry weights of maize shoots and roots}

Dry weight of maize shoots and root are shown in Figure 2. Dry weights of both shoots and roots were significantly influenced by application of AMF and/or EDTA. The highest dry weights of both shoots and roots were observed in AMF and least in case of EDTA. Results revealed 53, 119, and 21\% higher shoot dry matter yield from AMF treatment as compared to Control, EDTA, and EDTA-AMF, respectively. The respective increased fractions in case of roots dry matter were 63, 122, and $27 \%$. Furthermore, the results indicated that EDTA application seriously inhibited dry matter accumulation in shoots as well as roots and the values were even lower than the control.

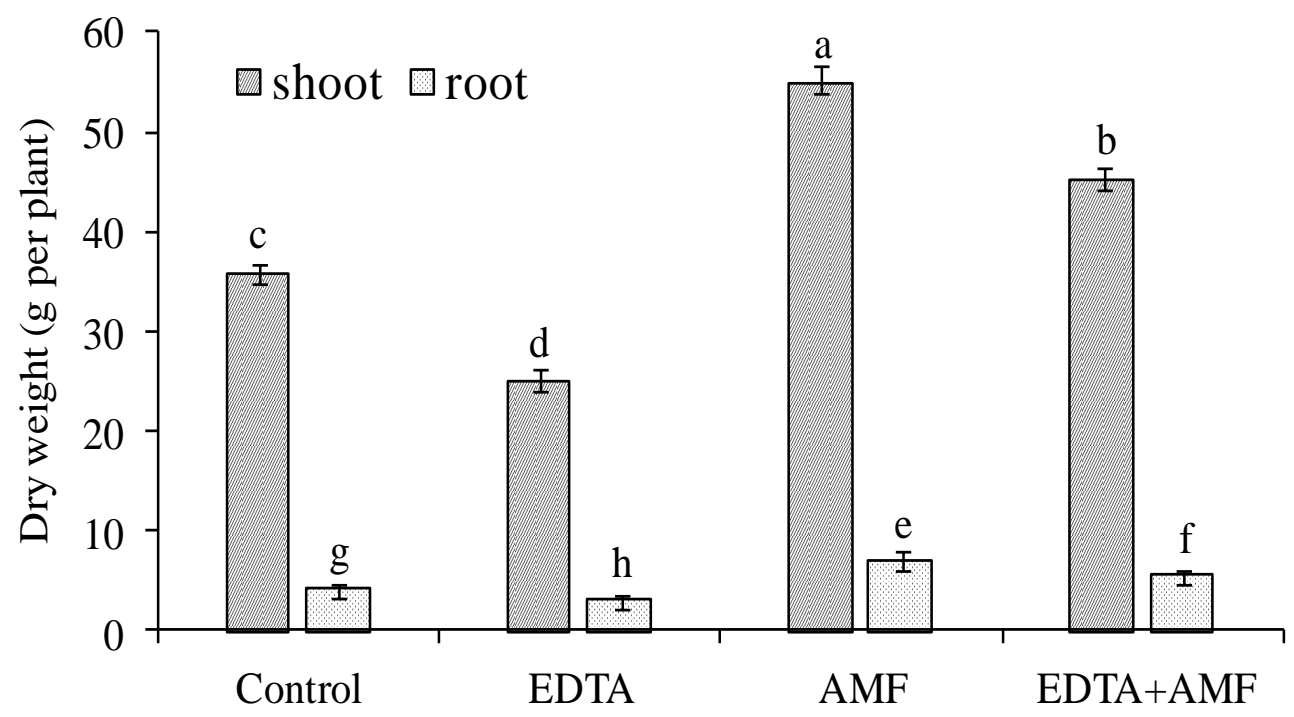

Figure 2. Dry weight in shoot and root affected by AMF and EDTA application. All the values are the mean of triplications. Different letters above columns indicate significant differences between means by LSD at $5 \%$ level 


\section{As concentrations in maize shoots and roots}

Results revealed greater total plant As accumulation from AMF, EDTA and their combination as compared to the control (Table 1). Among these treatments total As accumulation followed the order EDTA $>$ EDTA-AMF $>$ AMF $>$ Control. Out of the total As accumulation, greater fractions ended up in roots irrespective to the treatments. For the shoots, the highest value was observed in the plants treated with EDTA alone, and the lowest value was observed in the AMF-inoculated plants. Compared with EDTA alone, there was a decrease in As concentration in the plants treated with the EDTAAMF combination; however, statistical analysis revealed no difference. For the roots, the highest value was similarly observed in the plants treated with EDTA alone; however, the lowest value was observed in the control plants. Moreover, the results indicated that increase in As concentration was larger in the roots than in the shoots, and there were significant differences between them.

Table 1. Changes in average As concentration $(n=3)$ in shoot and root of maize plants. Different letters following the means indicate significant differences between means by LSD at

\begin{tabular}{c|c|c|c}
\multicolumn{4}{|c}{$5 \%$ level } \\
\hline \multirow{2}{*}{ Treatment } & Shoot & Root & Total \\
\cline { 2 - 4 } & $4.16 \mathrm{~b}$ & $92.07 \mathrm{~d}$ & $96 \mathrm{~d}$ \\
\hline Control & $7.58 \mathrm{a}$ & $258.72 \mathrm{a}$ & $266 \mathrm{a}$ \\
\hline EDTA & $3.88 \mathrm{c}$ & $168.49 \mathrm{c}$ & $172 \mathrm{c}$ \\
\hline AMF & $7.25 \mathrm{a}$ & $220.93 \mathrm{~b}$ & $228 \mathrm{~b}$ \\
\hline EDTA+AMF & \multicolumn{3}{|c}{}
\end{tabular}

\section{Enzyme activity}

Results revealed a significant effect of AMF, EDTA, and their combination on SOD and CAT activities as compared to the control (Fig. 3). SOD and CAT activities in the shoots and roots were significantly improved after AMF application and respectively increased by 37 and 30\%, as compared to the control plants. This increased fractions in case of AMF-EDTA combination was 29 and 16\%. In contrast, sharp inhibition of both these enzymes was observed in plants receiving EDTA only (Fig. 3). Consequently, SOD and CAT activities in the shoots decreased by $17 \%$ and $30 \%$ respectively, as compared with the control plants. Similar trend was observed for the roots; however, the increase in CAT activity was evidently larger than that in SOD activity (Fig. 3).

\section{Relative change in As in different species}

Figure 4 shows the relative changes if As speciation as affected by the addition of AMF, EDTA and their combination. We found that the ratio of different species to total As exhibited different changes in the rhizosphere soil. When EDTA was added alone, exchangeable As content increased to $13 \%$, which was 1.72 times greater than control, 2.7 times that AMF alone, and 1.8 times than the EDTA-AMF combination. However, the contents of all the other As forms in the EDTA treatment decreased as compared to the other treatments. Although the exchangeable As content in the rhizosphere soil treated with AMF alone was the lowest, the contents of carbonate As, Fe-Mn-bound As, and organic-bound As increased by $71 \%, 63 \%$, and $16 \%$ as compared to the control. 
Whereas the respective increased fraction was 212, 160, and 31\% than EDTA alone, and 15, 26 and 9\%, as compared with EDTA-AMF combination. Compared with AMF alone, the EDTA-AMF combination caused slight decreases in the contents of carbonate As, Fe-Mn-bound As, organic-bound As, and residual As, equivalent to the increase in exchangeable As content. The residual As was the greatest among all the As species, irrespective to the treatment.

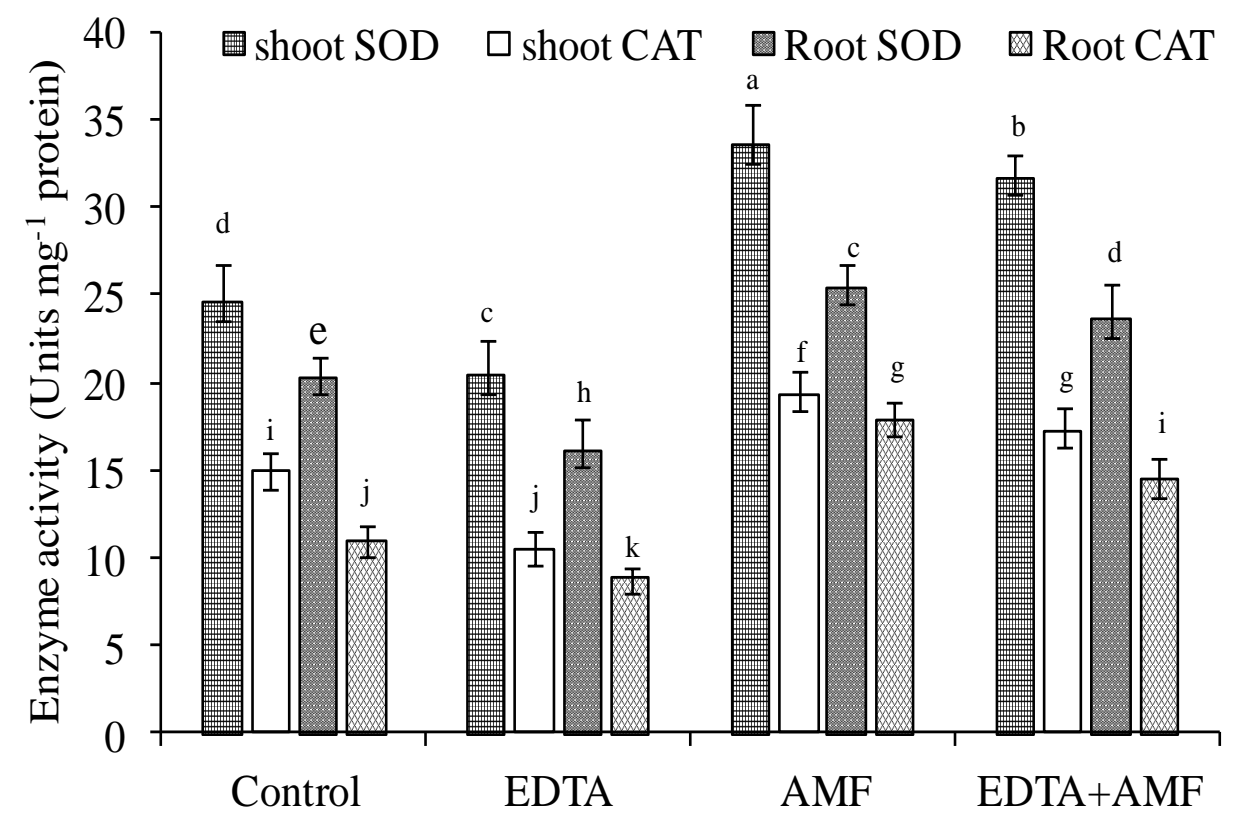

Figure 3. Enzyme activities of SOD and CAT in shoot and root affected by AMF and EDTA application. All the values are the mean of triplications. Different letters above columns indicate significant differences between means by LSD at 5\% level

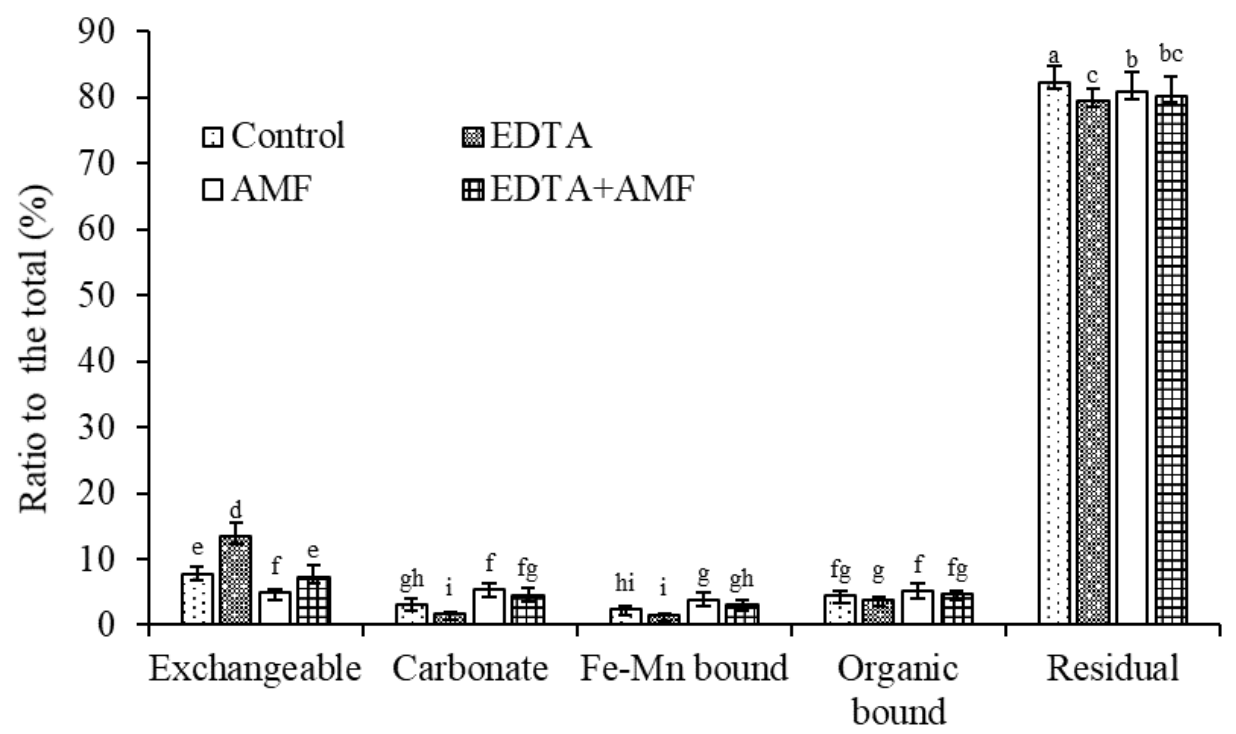

Figure 4. Relative change of As in different speciations as affected by AMF and EDTA application. All the values are the mean of triplications. Different letters above columns indicate significant differences between means by LSD at 5\% level 


\section{As extraction efficiency and biological enrichment factor}

As extraction efficiency is shown in Table 2 and followed the order EDTA $\geq$ EDTA $+\mathrm{AMF}>$ Control $>\mathrm{AMF}(\mathrm{P}<0.05)$. The order of As biological enrichment factor was EDTA + AMF $>$ AMF $>$ EDTA $>$ Control. The As extraction efficiency of maize plants treated with the EDTA-AMF combination was 1.71, and 1.95 folds greater that of the control, and AMF-treated plants, respectively, whereas the values were almost similar to that of EDTA Similarly, As biological enrichment factor was 2.84, 1.54, and 1.11 times greater than that of the control, EDTA-treated, and AMF-treated plants, respectively.

Table 2. Average As extraction efficiency and biological enrichment factor $(n=3)$ in maize plants. Different letters following the means indicate significant differences between means by $L S D$ at $5 \%$ level

\begin{tabular}{c|c|c}
\hline Treatment & As extraction efficiency $\left(\mathbf{m g ~ g}^{-\mathbf{1}}\right)$ & As biological enrichment factor $(\boldsymbol{\%})$ \\
\hline Control & $0.0347 \mathrm{~b}$ & $0.0403 \mathrm{~d}$ \\
EDTA & $0.0600 \mathrm{a}$ & $0.0743 \mathrm{c}$ \\
AMF & $0.0304 \mathrm{c}$ & $0.1029 \mathrm{~b}$ \\
EDTA+AMF & $0.0593 \mathrm{a}$ & $0.1145 \mathrm{a}$ \\
\hline
\end{tabular}

\section{Discussion}

\section{Mycorrhizal colonization}

Percentage root colonization is an important factor indicating the establishment of mycorrhizal associations by plants. This study showed that AMF application alone was favorable for mycorrhizal colonization, whereas the EDTA-AMF combination was observed to exert inhibitory effects to AMF survival (Fig. 1). These results were in line with some earlier studies who reported that EDTA addition to soil decreases the viability and number of AMF in the rhizosphere soil, although it is not lethal to the fungus (Marques et al., 2008; Tanwar et al., 2013).

\section{Plant dry weight}

Figure 2 shows that the order of the dry weights of both shoots and roots was AMF > EDTA + AMF > Control $>$ EDTA. EDTA treatment alone considerably decreased dry weight, probably because of the added phytotoxicity of EDTA and the heavy metal. Moreover, Figure 2 indicates that biomass accumulation in the mycorrhizal plants with and without EDTA treatment tended to increase. Various mechanisms have been reported to demonstrate that mycorrhizae can help plant species colonize metalcontaminated sites by improving $\mathrm{P}$ uptake by the plant, and thus, well-nourished plants show better growth (Lin et al., 2007; Tabrizi et al., 2015). Furthermore, AMF can effectively bind As to their cell walls, immobilize As in the fungal biomass, and subsequently improve plant tolerance to the metal-contaminated environment (Garg and Chandel, 2010; Joner et al., 2000). The positive effect of mycorrhizae on dry matter accumulation was partly offset by EDTA; the dry weight of plants treated with the EDTA-AMF combination was lower than that of the AMF-treated plants, yet significantly higher than that of the EDTA-treated plants. 


\section{As uptake and transport}

Roots are the first organs to be exposed to metal toxicity, and therefore, greater As accumulation was observed in the roots than in the shoots for all treatments. This might be regarded a strategy for preventing further metal translocation to the shoots and evidence of the operation of a potential tolerance mechanism in the root cells (Khudsar, 2008). It is well known that EDTA addition to contaminated soil can bring metals into solution through desorption of sorbed species and dissolution of precipitated compounds, thus maintaining their bioavailability for plant uptake (Marques, 2009; Norwell, 1984). Moreover, because of their neutral charge, metal-EDTA complexes are not blocked or bound by carboxyl groups or polysaccharides on the rhizodermal cell surface (Shahid et al., 2012). Therefore, root As concentration was the highest with the EDTA treatment (Table 1).

$\mathrm{Xu}$ et al. (2009) indicated that metal-EDTA complexes are transported through the apoplastic pathway, causing several-fold-stimulated metal translocation from roots to aerial plant parts, in agreement with our finding that, shoot As concentration was higher with the EDTA treatment than with other treatments. Extraradical hyphae of AMF can restrict heavy metal transport from soil to aboveground plant organs, and thus, may serve as a filter/biological barrier against heavy metal transport to plant shoots (Gaur and Adholeya, 2004; Schutzendubel and Polle, 2002). Therefore, shoot As concentration was observed to be minimum when AMF was applied alone. Although As was mainly retained in the root through immobilization by efficient mycorrhizal symbiosis, root As concentration with AMF alone was significantly lower than those with EDTA alone and EDTA-AMF combination, because of improved As uptake by EDTA.

\section{Relative change in different As species}

When EDTA was added to the soil, the ratios of the carbonate, Fe-Mn-bound, and organic-bound forms to total As were the lowest in the rhizosphere soil among all treatments, and the following mechanisms were mainly highlighted to explain this decrease caused by EDTA: (1) EDTA can decrease soil pH (Chen et al., 2004). Carbonates are sensitive to $\mathrm{pH}$, and decrease in $\mathrm{pH}$ triggers As release from carbonate minerals; (2) EDTA destabilizes the weak bond between metal ions and Fe-Mn oxides and organic matter, and releases the metal ions from these substances (Luciano et al., 2013). EDTA generally increases the exchangeable fractions of heavy metals in soil by forming soluble complexes with them, and this organic molecule is capable of releasing metals linked with different soil particles (Jean-Soro et al., 2012; Udovic and Lestan, 2009). These may be the reasons for the increase in exchangeable As content and decrease in residual As content in the rhizosphere soil after EDTA application alone.

Figure 4 indicates that AMF application had a negative impact on exchangeable As content in the rhizosphere soil; however, it had a positive impact on the contents of carbonate-bound As, Fe-Mn-bound As, organic-bound As, and residual As. The decrease in exchangeable As content and increase in bound As contents were beneficial to maize growth under As stress. The benefits conferred by the mycorrhizosphere for plant growth are: (1) metal ions are bound to extraradical mycelia, which form a dense network of up to several meters of hyphae, and have an unusually high metal sorption capacity (Janoušková and Pavlíková, 2010); (2) binding of metal ions to chitin in the fungal cell wall reduces metal concentration in the mycorrhizosphere soil (Göhre and 
Paszkowski, 2006); (3) AMF have high affinity for heavy metals, and are particularly suitable for fixing metal in the rhizosphere soil (Göhre and Paszkowski, 2006). These phenomena clearly explain the decrease in exchangeable As content and increase in bound As contents after AMF application alone. The ratio of exchangeable As to total As with the EDTA-AMF combination was evidently higher than that with the control and AMF alone, yet lower than that with EDTA alone, which was mainly because of mycorrhizal inhibition and EDTA promotion of EDTA-As chelation.

\section{Enzyme activity}

Under stress induced by As at $50 \mathrm{mg} \mathrm{kg}^{-1}$, the activities of both SOD and CAT increased significantly with AMF alone and EDTA-AMF combination; however, activities of both enzymes decreased with EDTA alone, in both shoots and roots, compared with the control (Fig. 3). Increase in enzyme activity is actually a defense mechanism activated by the AMF relationship wherein the metal-induced production of reactive oxygen species increases under metal stress, and activated SOD and CAT are responsible for scavenging the excessively accumulated reactive oxygen species to reduce oxidative stress (Saraswat and Rai, 2011). Concerning EDTA alone, the decrease in enzyme activity might be related to the increase in As bioavailability promoted by EDTA, which may result in enzyme inactivation.

\section{As extraction efficiency and biological enrichment factor}

Different responses of As extraction efficiency and biological enrichment factor are presented in Table 2. The decrease in extraction efficiency with AMF alone and EDTAAMF combination indicated that the growth dilution effect was likely to be an important protective mechanism provided by AMF (Zhang et al., 2005). However, the significant increase in biological enrichment factor with AMF alone and EDTA-AMF combination may be attributed to higher dry weight conferred by AMF and higher metal bioavailability facilitated by EDTA. Although EDTA application alone showed the highest extraction efficiency among all the treatments, biological enrichment factor was lower, excluding the control, because of growth inhibition caused by higher metal bioavailability.

\section{Conclusions}

We found that lone application EDTA significantly increased As extraction efficiency. However, it reduced plant yield, root colonization and antioxidant enzymatic activity. On the other hand, sole use of AMF, increased root colonization, maize dry matter yield and antioxidant enzyme activities, whereas decreased As extraction efficiency. Combine application of EDTA and AMF utilized the advantages of both EDTA and AMF to enhance As desorption from soil, improve the tolerance of maize plants to As stress, and increase As accumulation in shoots and roots. Thus, it showed a promising option for the remediation of heavy metal-polluted soil. This study warrants further investigations to optimize proportion of combination between AMF and EDTA. Moreover, the time and cost required for the phytoremediation of metal-polluted soil using maize should be considered. 
Acknowledgements. This work was supported by the (i) National Key Research and Development Program, Shandong Province (project No. 2016ZDJS11A07 and GG201709210196) and (ii) Key Research and Development Program, Yantai (Project No. 2017ZH097), Shandong China. We are equally indebted to Yantai Institute, China Agriculture University for providing research facilities.

\section{REFERENCES}

[1] Aebi, H. (1974): Catalase. - In: Bergmeyer, H. U. (eds.) Methods of Enzymatic Analysis. Academic Press Inc, New York, pp. 674-684.

[2] Audet, P., Charest, C. (2006): Effects of AM colonization on 'wild tobacco' plantsgrown in zinc-contaminated soil. - Mycorrhiza 16: 277-283.

[3] Beauchamp, C., Cridovich, F. (1971): Superoxide dismutase: improved assays and an assay application to acrylamide gels. - Annals of Biochemestry 44: 276-287.

[4] Bhargava, A., Carmona, F. F., Bhargava, M., Srivastava, S. (2012): Approaches for enhanced phytoextraction of heavy metals. - Journal of Environmental. Management 105: 103-120.

[5] Charriau, A., Lesven, L., Gao, Y., Leermakers, M., Baeyems, W., Ouddane, B., Billon, G. (2011): Trance metal behavior in riverine sediments: Role of organic matter and sulfides. - Appl. Geochemistry 26: 80-90.

[6] Chen, Y., Li, X,. Shen, Z. (2004): Leaching and uptake of heavy metals by tem different species of plants during an EDTA-assisted phytoextraction process. - Chemosphere 57: 187-196.

[7] Citterio, S., Prato, N., Fumagalli, P., Santagostino, A., Sgorbati, S., Berta, G. (2005): The arbuscular mycorrhizal fungus Glomus mosseae induces growth and metal accumulation changes in Cannabis sativa L. - Chemosphere 59: 21-29.

[8] Davies, F. T., Puryear, J. D., Newton, R. J., Egilla, J. N., Saraiva Grossi, J. A. (2001): Mycorrhhizal fungi enhance accumulation and tolerance of chromium in sunflower (Heliantbus ammuus). - Journal of Plant Physiology 158: 777-786.

[9] De la Rosa, G., Peralta-Videa, J. R., Cruz-Jimenez, G., Duarte-Gardea, M., MartinezMartinez, A., Cano-Aguilera, I., Sharma, N. C., Sahi, S. V., and Gardea-Torresdey, J. L. (2007): Role of ethylene diamine tetraacetic acid on lead uptake and translocation by tumbleweed (Salsola kali L.). - Environmental Toxicology and Chemistry 26: 10331039.

[10] Echevarri, G., Massoura, S., Sterckeman, T., Becquer, T., Schwartz, C., Morel, J. L. (2006): Assessment and control of the bioavailability of Ni in soils. - Environmental Toxicology and Chemistry 25: 643-651.

[11] Garg, N. Chandel, S. (2010): Arbuscular mycorrhizal networks: Process and functions. A review. - Agronomy for Sustainable Development 30: 581-599.

[12] Gaur, A., Adholeya, A. (2004): Prospect of arbuscular mycorrhizal fungi in phytoremediation of heavy metal contaminated soils. - Current Science 86: 528-534.

[13] Giasson, P., Jaouich, A., Gagné, S., Moutoglis, P. (2005): Arbuscular mycorrhizal fungi involvement in zinc and cadmium speciation change and phytoaccumulation. Remediation 15: 75-81.

[14] Goel, S., Gautam, A. (2010): Effect of chelating agents on mobilization of metal from waste catalyst. - Hydrometallurgy 101: 120-125.

[15] Göhre, V., Paszkowski, U. (2006): Contribution of the arbuscular mycorrhizal symbiosis to heavy metal phytoremediation. - Planta 223: 1115-1122.

[16] Hadi, F., Bano, A., Fuller, M. P. (2010): The improved phytoextraction of lead $(\mathrm{Pb})$ and the growth of maize (Zea mays, L.): The role of plant growth regulators $\left(\mathrm{GA}_{3}\right.$ and IAA) and EDTA alone and in combinations. - Chemosphere 80: 457-462.

[17] Hildebrandt, U., Kaldorf, M., Bothe, H. (1999): The zinc violer and its colonization by arbuscular mycorrhizal fungi. - Journal of Plant Physiology 154: 709-717. 
[18] Janoušková, M., Pavlíková, D. (2010): Cadmium immobilization in the rhizosphere of arbuscular mycorrhizal plants by fungal extra radical mycelium. - Plant and Soil 332: 511-520.

[19] Janousková, M., Pavlíková, D., Macek, T., Vosátka, M. (2005): Arbuscular mycorrhiza decreases cadmium phytoextraction by transgenic tobacco with inserted metallothionein. - Plant and Soil 272: 29-40.

[20] Jean-Soro, L., Bordas, F., Bollinger, J. C. (2012): Column leaching of chromium and nickel from a contaminated soil using EDTA and citric acid. - Environmental Pollution 164: 175-181.

[21] Joner, E. J., Briones, R., Leyval, C. (2000): Metal-binding capacity of arbuscularmyccorhizal mycelium. - Plant and Soil 226(2), 227-234.

[22] Khudsar, T., Arshi, A., Siddiqi, T. O., Mahmooduzzafar, Iqbal, M. (2008): Zinc-induced changes in growth characters, foliar properties, and $\mathrm{Zn}$-accumulation capacity of pigeon pea at different stages of plant growth. - Journal of Plant Nutrition 31: 281-306.

[23] Koske, R. E., Gemma, J. N. (1989): A modified procedure for staining roots to detect VA mycorrhizae. - Mycological Research 92: 486-505.

[24] Lin, A., Zhang, X., Wong, M., Ye, Z., Lau, L., Wang, Y., Zhu, Y. (2007): Increase of mutimetal tolerance of three leguminous plants by arbuscular mycorrhizal fungi colonization. - Environmental Geochemistry and Health 29: 473-481.

[25] Luciano, A., Viotti, P., Torretta, V., Mancini, G. (2013): Numerical approach to modeling pulse-mode soil flushing on Pb-contaminated soil. - Journal of Soil and Sediments 13: 43-45.

[26] Marques, A. P. G. C., Oliveira, R. S., Sam-Ardjieva, K. A., Pissarra, J., Rangel, A. O. S. S., Pissarra, J., Castro, P. M. L. (2008): EDDS and EDTA-enhanced zinc accumulation by Solanum nigrum inoculated with arbuscular mycorrhizal fungi grown in contaminated soil. - Chemosphere 70: 1002-1014.

[27] Marques, A. P. G. C., Rangel, A. O. S. S., Castro, P. M. L. (2009): Remediation of heavy metal contaminated soils: phytoremediation as a potentially promising clean-up technology. - Critical Reviews in Environmental Science and Technology 39: 622-654.

[28] McGrath, S. P., Zhao, F. J. (2003): Phytoextraction of metals and metalloids from contaminated soils. - Current Opinion in Biotechnology 14: 227-282.

[29] Meier, S., Borie, F., Bolan, N., Cornejo, P. (2012): Phytoremediation of metal-polluted soils by arbuscular mycorrhizal fungi. - Critical Reviews in Environmental Science and Technology 42(7): 741-775.

[30] Norwell, W. A. (1984): Comparison of chelating agents as extractants for metals in diverse soil materials. - Soil Science Society of America Journal 48: 1285-1292.

[31] Pandey, V. C. (2012): Phytoremediation of heavy metals from fly ash pound by Azolla caroliniana. - Ecotoxicology and Environmental Safety 82: 8-12.

[32] Saraswat, S., Rai, J. P. N. (2011): Mechanism of Metal Tolerance and Detoxification in Mycorrhizal Fungi. - In: Khan, M. S., Zaidi, A. (eds.) Biomanagement of MetalContaminated Soil, Springer, The Netherlands, pp. 225-240.

[33] Sarwar, N., Imran, M., Shaheen, M. R., Ishaque, W., Kamran, M. A., Matloob, A., Rehim, A., Hussain, S. (2017): Phytoremediation strategies for soils contaminated with heavy metals: Modifications and future perspectives. - Chemosphere 171: 710-721.

[34] Schutzendubel, A., Polle, A. (2002): Plant responses to abiotic stresses: heavy metal oxidative stress and protection by mycorrhhization. - Journal of Experimental Botany 53: 1351-1365.

[35] Seth, C. S. (2011): A review on mechanisms of plant tolerance and role of transgenic plants in environmental clean-up. - The Botanical Review 78: 32-62.

[36] Shabir, R., Abbas, G., Saqib, M., Shahid, M., Shah, G. M., Akram, M., Ashraf, F. (2018): Phytoremediation of $\mathrm{Cd}$ by Acacia nilotica $\mathrm{L}$. as affected by $\mathrm{NaCl}$ salinity. - International Journal of Phytoremediation 7: 739-746. 
[37] Shah, G. M., Rashid, M. I., Shah, G. A., Groot, J. C. J., Lantinga, E. A. (2013): Mineralization and herbage recovery of animal manure nitrogen after application to various soil types. - Plant and Soil 365(1-2): 69-79.

[38] Shah, G. M., Shah, G. A., Groot, J. C. J., Raza, M. A. S., Shahid, N., Lantinga, E. A. (2016): Nitrogen recovery and dry matter production of silage maize as affected by the application of solid cattle manure stored under different conditions. - Journal of Soil Science and Plant Nutrition 16(3): 591-603.

[39] Shahid, M., Pinelli, E., and Dumat, C. (2012): Review of Pb availability and toxicity to plant in relation with metal speciation: role of synthetic and natural organic ligands. Journal of Hazardous Material 219-220: 1-12.

[40] Sinha, S., Mishra, R. K., Sinam, G., Mallick, S., Gupta, A. K. (2013): Comparative evaluation of metal phytoremediation potential of trees, grass, and flowering with the hyperaccumulator plants from tannery-wastewater-contaminated soil in relation with physicochemical properties. - Soil Sediment Contamination 22: 958-983.

[41] Tabrizi, L., Mohammadi, S., Delshad, M., Zadeh, B. M. (2015): Effect of arbuscular mycorrhizal fungi on yield and phytoremediation performance of pot marigold (Calendula officinalis L.) under heavy metals stress. - International Journal of Phytoremediation 17: 1244-1252.

[42] Tang, Y. T., Deng, T., Wu, Q. H., Wang, S. Z., Qiu, R. L., Wei, Z. B., Guo, X. F., Lei, M., Chen, T. B., Echevarria, G., Sterckeman, T., Simonnot, M. O., Morel, J. L. (2012): Designing cropping system for metal-contaminated sites: A review. - Pedosphere 22: 470-488.

[43] Tanwar, A., Aggarwal, A., Charaya, M. U., Kumar, P. (2013): Enhancement of lead uptake by fenugreek using EDTA and glomus mosseae. - Communication in Soil Science and Plant Analysis 44: 3431-3443.

[44] Tomé, V. F., Blanco, R. P., Lozano, J. C. (2009): The ability of Helianthus annuus L. and Brassica juncea to uptake and translocate natural uranium and 226Ra under different milieu conditions. - Chemosphere: 74: 293-300.

[45] Trotta, A., Falaschi, P., Cornara, L., Minganti, V., Fusconi, A., Drava, G., Berta, G. (2006): Arbuscular mycorrhizae increase the arsenic translocation factor in the As hyperaccumulating fern Pteris vittata L. - Chemosphere: 65: 74-81.

[46] Udovic, M., Lestan, D. (2009): $\mathrm{Pb}, \mathrm{Zn}$ and Cd mobility, availability and fractionation in aged soil remediated by EDTA leaching. - Chemosphere 74: 1367-1373.

[47] Wang, X. P., Zabowski, D. (1998): Nutrient composition of Douglas-fir rhizosphere and bulk soil solutions. - Plant and Soil 200: 13-20.

[48] Xu, W., Li, W., He, J., Balwant, S., and Xiong, Z. (2009): Effects of insoluble Zn, Cd, and EDTA on the growth, activities of antioxidant enzymes and uptake of $\mathrm{Zn}$ and $\mathrm{Cd}$ in Vetiveria zizanioides. - Journal of Environmental Science 21: 186-192.

[49] Yang, G. Y., Li, F. B., Wan, H. F. (2003): Changes in the contents of heavy metals in pig manure compositing (in Chinese). - Ecology and Environment 12(4): 412-414.

[50] Yang, J. R., Che, Y. H. (1986): Ecological impact assessment for opencut coal mine. Acta Scientiae Circumstantiae 6(1): 1-7.

[51] Zhang, X. H., Zhu, Y. U., Chen, B. D., Lin, A. J., Smith, S. E., Smith, F. A. (2005): Arbuscular mycorrhizal fungi contribute to resistance of upland rice to combined metal contamination of soil. - Journal of Plant Nutrition 28: 2065-2077. 